\title{
Retroposition of autosomal mRNA yielded testis-specific gene family on human Y chromosome
}

\section{Bruce T. Lahn \& David C. Page}

Nature Genet. 21, 429-433 (1999).

Due to an error on the part of Nature Genetics, Figs 4 and 5 were mislabelled. With respect to Fig. 4, human CDY, which was labelled "autosomal", should have been labelled "Y-linked". The correct version is printed below. With respect to Fig. 5, the legend read "or autosomal segments; data not shown". It should have read "or autosomal segments; not shown in figure". Where the legend read "subsequent amplification; data not shown" it should have read "subsequent amplification; not shown in figure". The correct version is printed below. The abstract stated, incorrectly, that the CDYL gene is "located on human chromosome 13 and mouse chromosome 6." As stated elsewhere in the text, CDYL is located on human chromosome 6 and mouse chromosome 13.
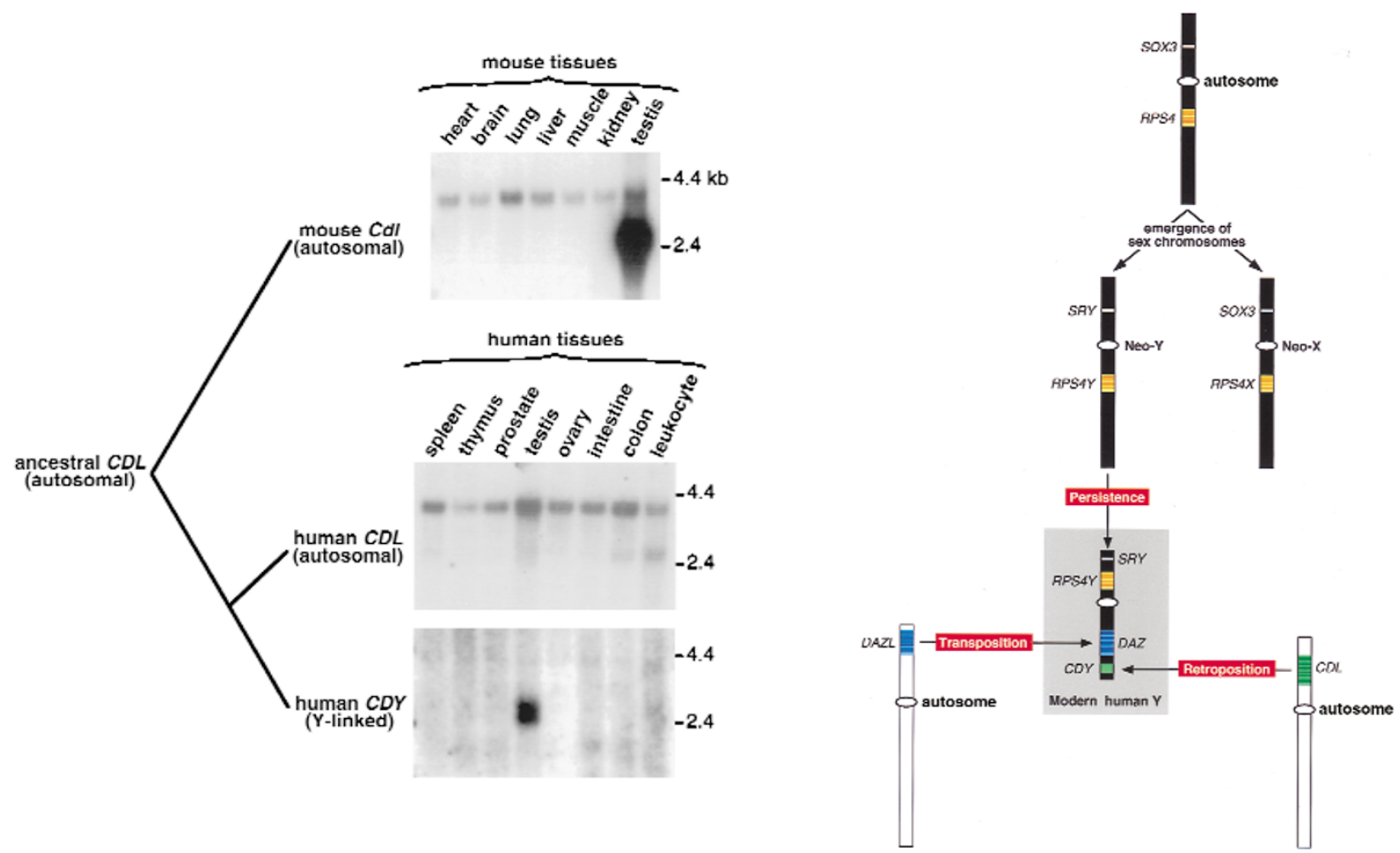

Fig. 4 Tissue distributions of mouse Cdyl, human CDYL and human CDY transcripts. Northern blots incubated with cDNA fragments corresponding to the entire coding sequence of either mouse Cdyl (top), human CDYL (middle), or human CDY1 (bottom), reveal tissue expression patterns; the phylogenic relationship of these genes (illustrated on left) is based on data presented in Fig. 3.

Fig. 5 Schematic representation of three molecular evolutionary processes that contributed genes to human NRY. Persistence (top): an autosomal pair gave rise to the neo-Y and neo-X (subsequently enlarged by fusion with other autosomes or autosomal segments; not shown in figure; refs 23,24). SRY, RPS4Y and several other genes derived from these ancestral autosomes persist as Xhomologous genes in the human NRY (refs 1-4,25). Transposition: the DAZ genes arose by transposition (and subsequent amplification; not shown in figure) of autosomal genomic DNA containing the entire DAZL transcription unit $^{5}$. Retroposition: the CDY genes arose by integration (and subsequent amplification; not shown in figure) of a reverse-transcribed copy of a processed mRNA derived from the autosomal CDYL gene. Gene sizes are not to scale.

\section{Acetylated histones are associated with FMR1 in normal but not fragile $\mathrm{X}$-syndrome cells}

Bradford Coffee et al.

Nature Genet. 22, 98-101 (1999).

Due to an error on the part of Nature Genetics, the date of receipt for this Letter read 14 November 1998. The date of receipt should have read 14 January 1999. 